\title{
Modelization of earth electrode excited by atmospheric discharges based on FEM
}

\author{
J.M. Bueno Barrachina ${ }^{1}$, , C.S. Cañas Peñuelas ${ }^{2}$, S. Catalán Izquierdo ${ }^{2}$, A. Quijano López ${ }^{2}$ \\ ${ }^{1,2}$ Instituto de Tecnología Eléctrica \\ Av. Juan de la Cierva, 24 \\ Parque Tecnológico de Valencia \\ 46980 Paterna - Valencia - Spain \\ Phone number:+0034 961366670 /Fax number:+0034 961366680 \\ e-mail: jmanuel.bueno@ite.es; cesar.canas@ite.es; $\underline{\text { saturnino.catalan@ite.es; alfredo.quijano@ite.es }}$
}

\begin{abstract}
.
The aim of this paper is to obtain the distribution of tensions in the land excited by currents type ray using different types of electrodes: the goad electrodes and the deep goad electrodes, and as an exceptional case an electrode type drags was used. In this work, the program ANSYS ${ }^{\circledR}$ that is based on the finite elements method (FEM) was used. After the simulation of the distribution of tensions, different parameters were obtained, such as the tensions of step (Vp) and of contact ( $\mathrm{Vc}$ ) which determine the security of the installation of put in the earth (PE) protection
\end{abstract}

\section{Key words}

Earth electrodes, grounding systems, protection systems, wind energy.

\section{Introduction}

In Wind Energy generation parks, where the impacts type rays are numerous, it has been demonstrated that the response of the electrodes varies depending on the excitation. Nowadays the main variable in the installation of a PE electrode is resistivity of land. This variable is usually measured by a tellurometer that consists in injecting DC in the land. In this way, the dimensions of electrode to obtain one prescribed resistance can be calculated. The expressions which are used to obtain the resistance of $\mathrm{PE}$ of an electrode, consider that it behaves like a resistance. Nevertheless its behaviour depends on the type of excitation, i.e., if sine excitations are considered, the PE behaves as a resistance, inductance and capacitance (RLC). Moreover, its value depends on the frequency and the amplitude of the excitation.

In order to determine the appropriate electrode of PE for protection opposite to a stroke currents, it is necessary to install several types of electrodes in the zone to protect. Subsequently a current type ray which is obtained using generating source is injected to each type of electrode sequentially. After the evaluation of the results, only those electrode which fulfils the required condition will be remained installed. This method is valid but it is not efficient, since for each type of land it is necessary to repeat all the tests, and it will increase considerably the economic and temporary cost.

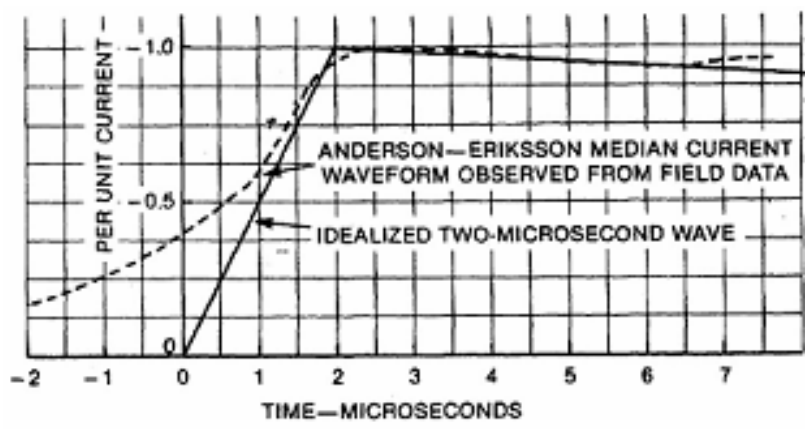

Fig. 1. The idealized stroke current waveshape used in the simplified method [1].

The models proposed in this paper are able to evaluate the behaviour of a PE electrode opposite to injections of idealized currents type ray $1.2 / 50 \mu \mathrm{s}$, for different types from land and different configurations from electrodes (Figure 1).

\section{Model and Simulation}

Continuing the investigation of Navarro et al. [2] that managed to obtain different correlations between the parameters from an grounding electrode. These correlations are used for different configurations from electrodes and different values from resistivity of the soil. In this case we are going to analyze three typologies of grounding electrode.

The first electrode modelled and simulated is the electrode of goad. This is the most popular electrode in the installations of PE, this electrode is denominated electrode 1 (Figures 2 and 3 ).

The second electrode (electrode 2) modelled is the electrode 1 but buried to certain depth. 
The third electrode modelled is a formation with three electrodes 1 at certain angle $\alpha$ with the horizontal, this formation is named electrode type drags (Figure 4).

The simulation process inject the ray current in de superior face of electrode, and calculate the land distribution of tensions.

For the simulation is employed the different resistivity of lands and the different dimensions and typologies of electrodes.

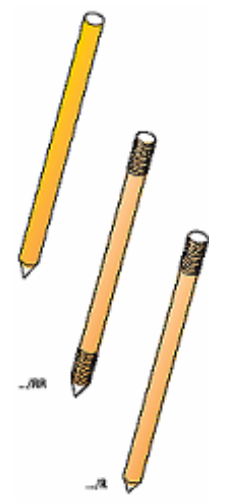

Fig. 2: Commercial electrode of goad, electrode 1.

NN

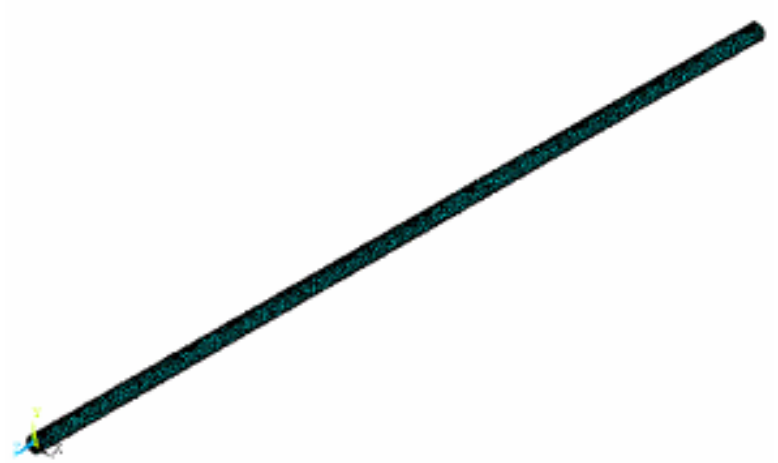

Fig. 3. FEM model of the electrode 1.

NN

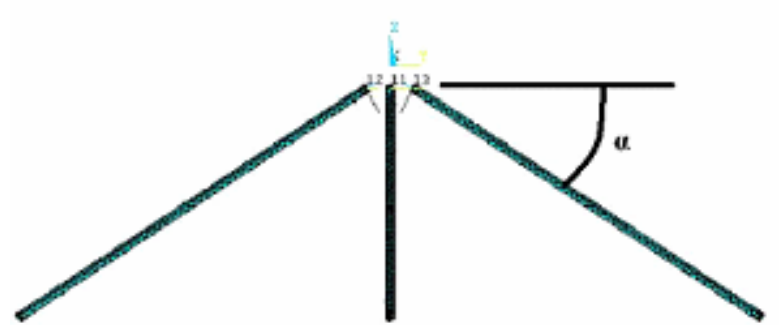

Fig. 4. FEM model of the electrode type drags.

The terrain modelled (Figure 5) is very extended for considered the reference of potentials ( 0 Volts).

The inductive coupling in the electrode type drags is calculated witch the methodology exposed in the work of Cortina et al. [3].

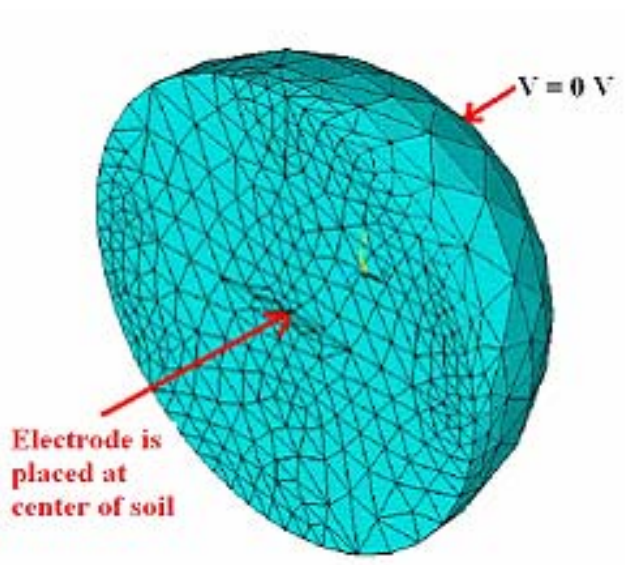

NN

Fig. 5. Terrain modelled.

\section{Results}

Figure 6 and Table I shows the voltage distribution in the soil surface, and figure 7 shows the theoretical and the simulated results, for a copper goad of 1 meter of length and 0.02 meter of diameter and a soil resistivity equal to $100 \Omega \mathrm{m}$.

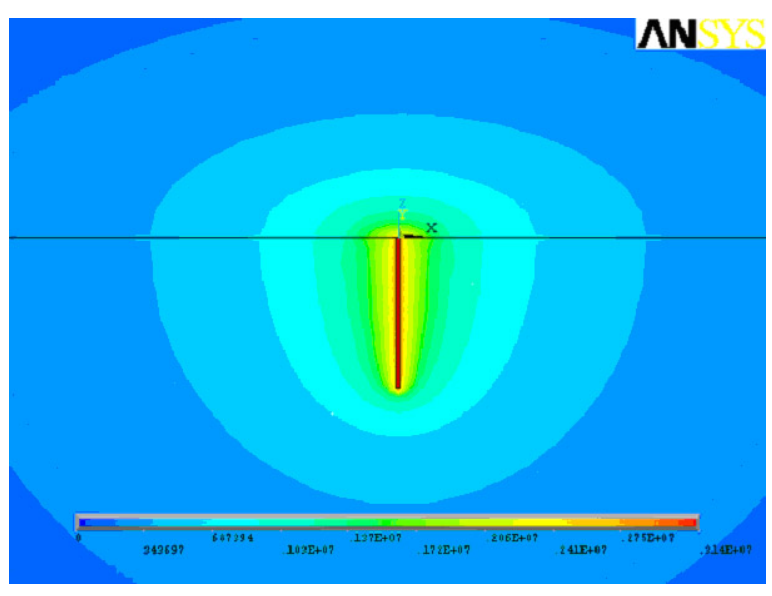

Fig. 6. Voltage distribution in the soil surface, $31 \mathrm{kA}$ direct current.

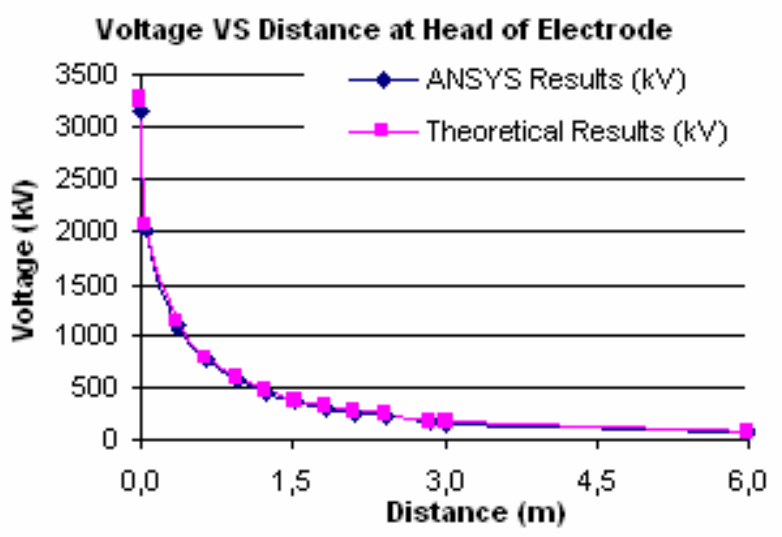

Fig. 7. Theoretical and the simulated results. 
TABLE I: Voltage VS Distance at Head of Electrode

\begin{tabular}{|c|c|c|c|}
\hline Distance (m) & $\begin{array}{c}\text { ANSYS } \\
\text { Results (kV) }\end{array}$ & $\begin{array}{c}\text { Theoretical } \\
\text { Results (kV) }\end{array}$ & Error (\%) \\
\hline 0,0000 & 3142,4000 & 3266,2139 & $-3,79$ \\
\hline 0,0100 & 3142,4000 & 3232,1741 & $-2,78$ \\
\hline 0,0600 & 2016,5000 & 2072,0519 & $-2,68$ \\
\hline 0,3540 & 1085,7000 & 1130,4435 & $-3,96$ \\
\hline 0,6480 & 761,9900 & 787,9360 & $-3,29$ \\
\hline 0,9420 & 573,7800 & 603,3552 & $-4,90$ \\
\hline 1,2360 & 446,3400 & 469,3381 & $-4,90$ \\
\hline 1,5300 & 364,0000 & 379,2391 & $-4,02$ \\
\hline 1,8240 & 303,3700 & 321,5513 & $-5,65$ \\
\hline 2,1180 & 256,3700 & 275,2374 & $-6,85$ \\
\hline 2,4120 & 220,1400 & 237,0792 & $-7,14$ \\
\hline 2,8530 & 174,9700 & 172,9339 & 1,18 \\
\hline 3,0000 & 158,3700 & 164,4601 & $-3,70$ \\
\hline 6,0000 & 64,8740 & 67,8398 & $-4,37$ \\
\hline
\end{tabular}

With the previous simulation the resistive part of model has been validated, that the simulation has been made injecting a DC of $31 \mathrm{kA}$.

The next step is inject a stroke current $1,2 / 50$ of $31 \mathrm{kA}$ at the same model developed.

The result of the simulation is represented in Figure 8 and .in the Table II.

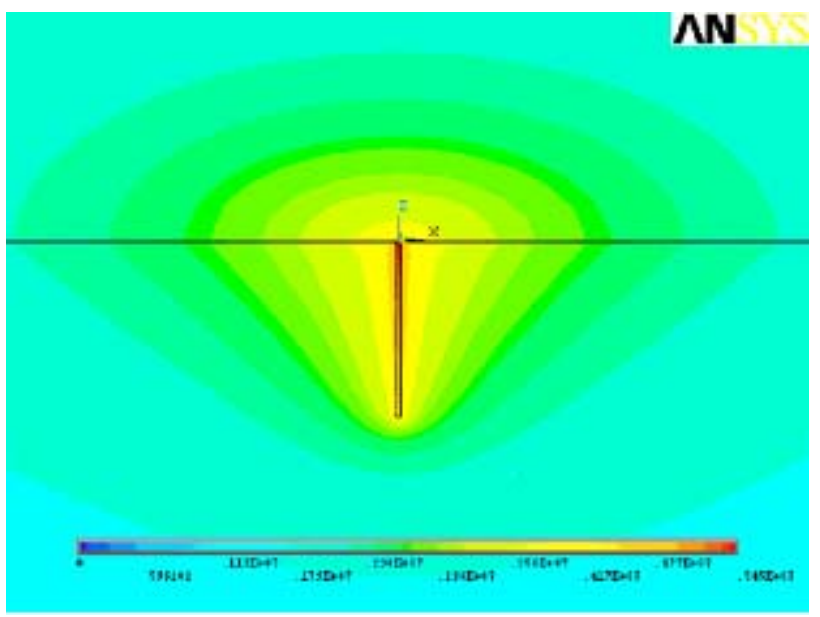

Fig. 8: Max. voltage distribution in the soil surface, $31 \mathrm{kA}$ stroke current.

The voltages obtained in the simulation with stroke currents are more elevated than the voltages obtained in the case with DC.

The form of the equipotential lines which they surround to the electrode has varied with respect at DC case.

These observed variations are based on the existence of an inductive component for the case of the stroke current, and that not shows in DC case.
TABLE II: Max. voltage VS Distance at Head of Electrode

\begin{tabular}{|c|c|}
\hline Distance $(\mathrm{m})$ & ANSYS Results $(\mathrm{kV})$ \\
\hline 0,000 & 5450,96 \\
\hline 0,010 & 5450,93 \\
\hline 0,060 & 4325,68 \\
\hline 0,354 & 3375,73 \\
\hline 0,648 & 3007,70 \\
\hline 0,942 & 2763,50 \\
\hline 1,236 & 2568,47 \\
\hline 1,530 & 2412,06 \\
\hline 1,824 & 2281,28 \\
\hline 2,118 & 2162,87 \\
\hline 2,412 & 2063,15 \\
\hline 2,853 & 1926,69 \\
\hline 3,000 & 1876,73 \\
\hline 6,000 & 1383,02 \\
\hline
\end{tabular}

The next figure shows the voltage at head of electrode

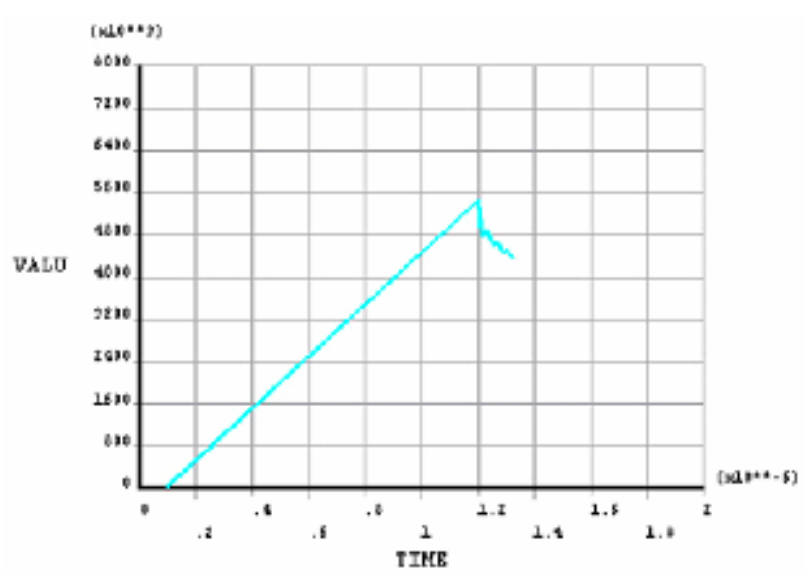

Fig. 9: Voltage at head of electrode.

With the collected data we come to calculate the inductance of grounding electrode.

For the next calculations of the inductance, a serial RL circuit (Figure 10) has been considered for represented the grounding electrode.

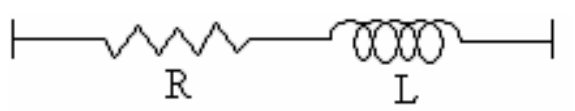

Fig. 10: Serial RL circuit considered

The next equation is the electric equation of this circuit.

$$
v(t)=R \cdot i(t)+L \cdot \frac{d i(t)}{d t}
$$

Applying this equation to the obtained results, the inductance when the voltage is max, is:

$$
L=89,65 \mu H
$$


The following simulated model of grounding electrode, is the same goad of first model, but buried to 10 meters of depth. The soil resistivity is the same value has been taken that in previous model.

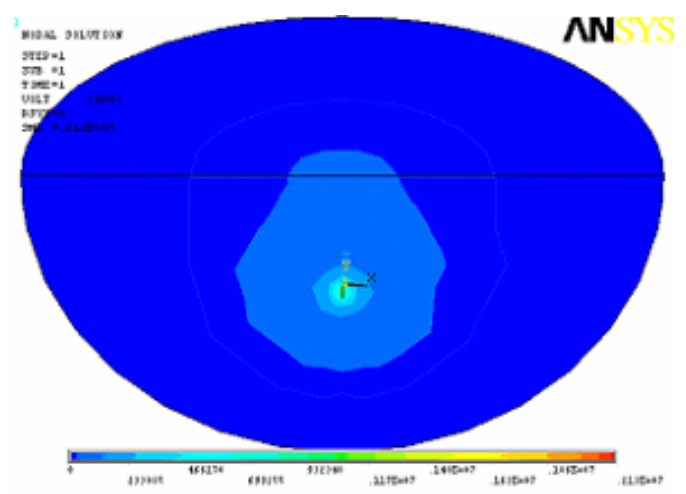

Fig. 11. Voltage distribution in the soil surface, $31 \mathrm{kA}$ direct current.

Figure 11 shows he voltage distribution in the soil surface, during the injection of a $31 \mathrm{kA} \mathrm{DC}$.

The next figure show the equipotential lines around of electrode.

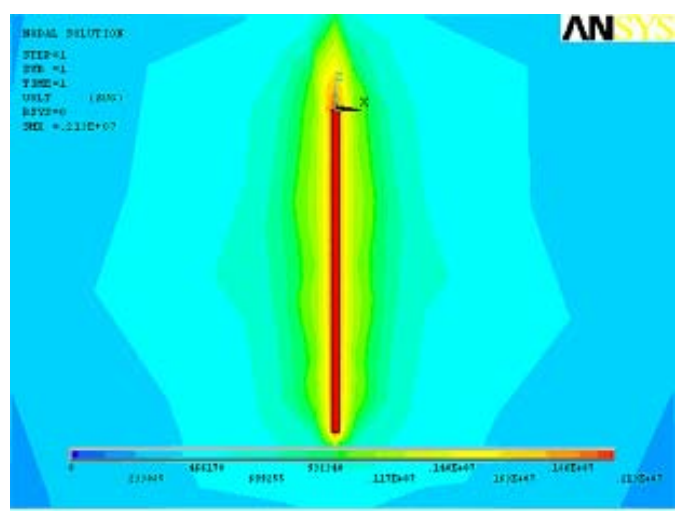

Fig. 12. Equipotential lines around of goad.

The next step is inject a stroke current $1,2 / 50$ of $31 \mathrm{kA}$ at the same model developed.

Figures 12 and 13 show the result of the simulation.
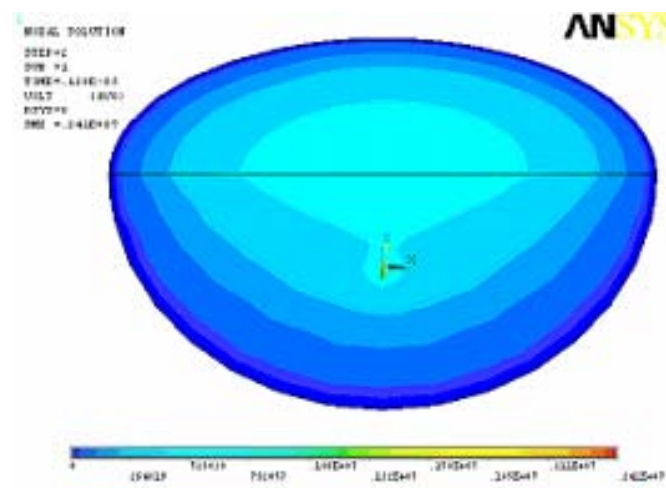

Fig. 13: Max. voltage distribution in the soil surface, $31 \mathrm{kA}$ stroke current.

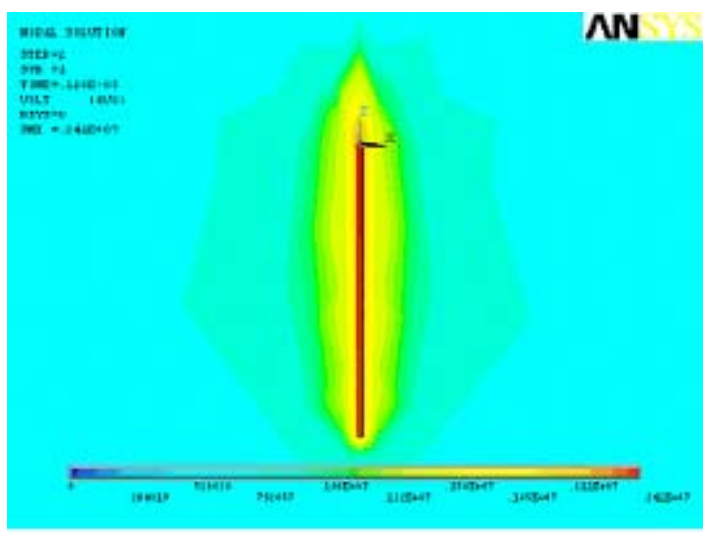

Fig. 14: Equipotential lines around of goad.

TABLE III: Max. voltage VS Distance at Head of Electrode

\begin{tabular}{|c|c|c|c|}
\hline $\begin{array}{c}\text { Distance } \\
(\mathrm{m})\end{array}$ & $\begin{array}{c}\text { ANSYS } \\
\text { Transient Results } \\
(\mathrm{kV})\end{array}$ & $\begin{array}{c}\text { ANSYS DC } \\
\text { Results }(\mathrm{kV})\end{array}$ & $\begin{array}{c}\text { Difference } \\
(\mathrm{kV})\end{array}$ \\
\hline $\begin{array}{c}10 \text { meters } \\
\text { of deep }\end{array}$ & 2413,9 & 2131,10 & 282,80 \\
\hline 0,00 & 745,7 & 39,03 & 706,72 \\
\hline 0,28 & 743,1 & 39,03 & 704,08 \\
\hline 1,20 & 737,0 & 38,11 & 698,91 \\
\hline 1,26 & 736,0 & 38,08 & 697,94 \\
\hline 1,31 & 735,9 & 38,01 & 697,94 \\
\hline 4,40 & 685,8 & 33,23 & 652,60 \\
\hline 8,52 & 581,5 & 23,88 & 557,58 \\
\hline
\end{tabular}

Table III shows the values computed for ANSYS [4] in this simulation.

The distance in table III is refered at centre of electrode.

Introducing the values of table III in equation (1), the impedance of grounding electrode is obtained at the moment at which the tension is Max.

$$
L=27,44 \mu H
$$

The third and last electrode modelled in this paper, is the electrode type drags, compound of three goads of 1 meter in length, forming an angle of $90^{\circ}$ respect to the horizontal and $120^{\circ}$ among them. The soil resistivity considered is $100 \Omega \mathrm{m}$.

Figures 15 an 16 shows the voltage distribution in the soil surface, during the injection of a $31 \mathrm{kA} \mathrm{DC}$ and stroke current respectively.. 


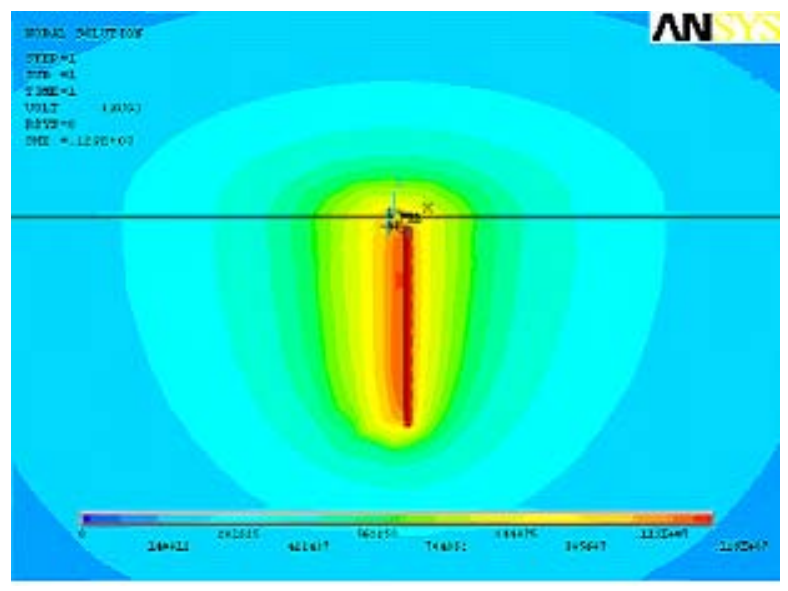

Fig. 15. Equipotential lines around of goad.

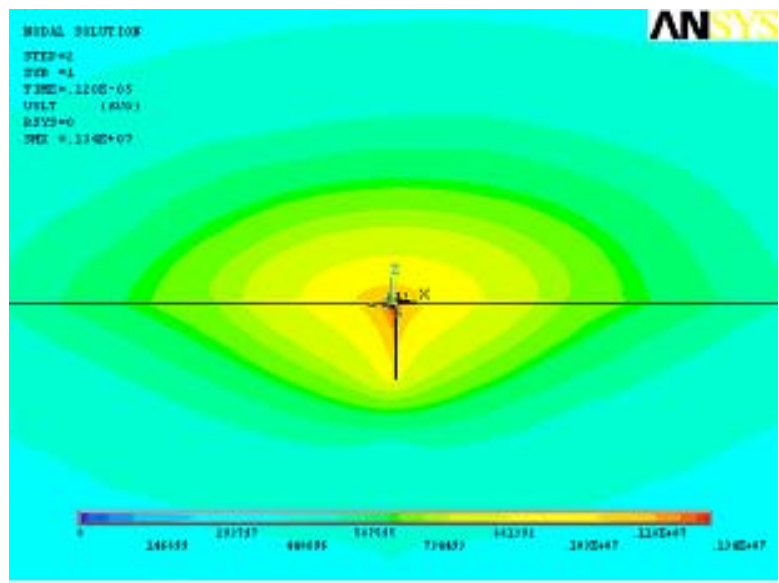

Fig. 16. Equipotential lines around of goad.

Table IV shows the values computed for ANSYS in this simulation.

TABLE IV: Max. voltage VS Distance at Head of Electrode

\begin{tabular}{|c|c|c|c|}
\hline $\begin{array}{c}\text { Distance } \\
(\mathrm{m})\end{array}$ & $\begin{array}{c}\text { ANSYS } \\
\text { Transient } \\
\text { Results }(\mathrm{kV})\end{array}$ & $\begin{array}{c}\text { ANSYS DC } \\
\text { Results }(\mathrm{kV})\end{array}$ & $\begin{array}{c}\text { Difference } \\
(\mathrm{kV})\end{array}$ \\
\hline 0,00 & 1326,90 & 1181,50 & 145,40 \\
\hline 0,20 & 1199,70 & 817,56 & 382,14 \\
\hline 0,40 & 1109,20 & 589,15 & 520,05 \\
\hline 0,60 & 1044,80 & 462,18 & 582,62 \\
\hline 0,80 & 990,00 & 372,21 & 617,79 \\
\hline 1,00 & 938,80 & 311,08 & 627,72 \\
\hline 1,40 & 847,47 & 226,44 & 621,03 \\
\hline 1,60 & 808,04 & 196,33 & 611,71 \\
\hline 1,80 & 773,33 & 170,11 & 603,22 \\
\hline 2,00 & 733,20 & 137,40 & 595,80 \\
\hline 8,50 & 356,06 & 21,65 & 334,41 \\
\hline
\end{tabular}

Introducing the values of table IV in equation (1), the impedance of grounding electrode is obtained at the moment at which the tension is Max.

$$
L=24,38 \mu H
$$

In order to validate the model in transient state, the results obtained in this paper were compared with the obtained by other authors [5], who defended the deformation of equipotential lines around the electrode due to its the inductive effect opposite to stroke currents.

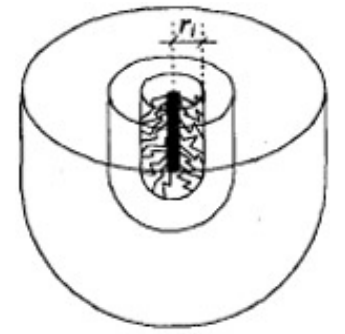

Fig. 17: Model proposed by Liew [5].

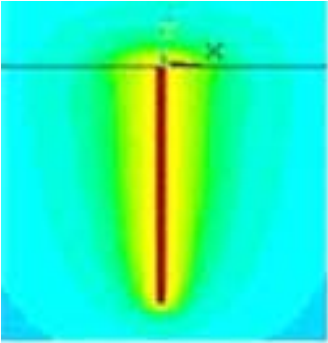

a)

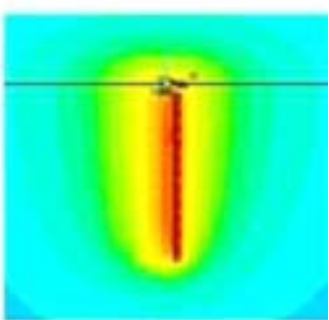

b)
Fig. 18: Equipotential lines at $31 \mathrm{kA} \mathrm{DC}$ for one goad (a) and three goads (B).

Figure 17 show the model proposed by Liew [5], this model is more exact than the model proposed by Geri [5]. If compare the distributions obtained in ANSYS (Figure 18) with the distribution proposed by Liew, this distribution are identical form.

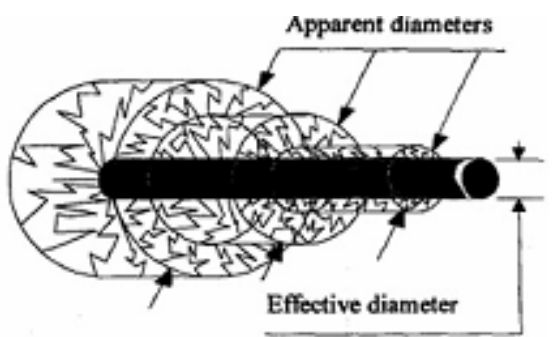

Fig. 19: Model proposed by A. Geri [5] at case of excitation type stroke current.

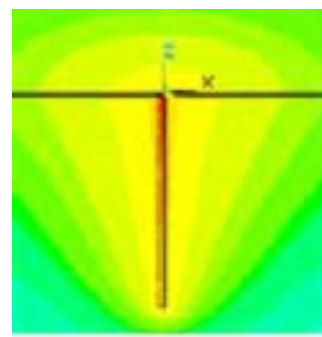

a)

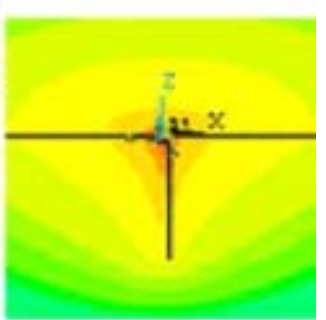

b)
Fig. 20: Equipotential lines at $31 \mathrm{kA}$ stroke current for one goad (a) and three goads (B). 
Figure 19 show the model proposed by A. Geri [5]. If compare the distributions obtained in ANSYS (Figure 20) with the distribution proposed by A. Geri, this distribution are similar form.

\section{Conclusion}

The main advantage in this models, is that any parameter can be changed, i.e., the excitation current, the resistivity, the magnetic permittivity, and the forms of the grounding electrodes.

The limitation of the proposed models is that the capacity of the grounding electrode was not considered, which is very important to obtain a more realistic model of the grounding electrode.

\section{References}

[1] [Anon], "A Simplified Method for Estimating Lightning Performance of Transmission-Lines," IEEE Transactions on Power Apparatus and Systems., vol. 104, no. 4, pp. 919-932, Apr.1985.

[2] Óscar Navarro Carrasco, César S.Cañas Peñuelas, Rafael García Fernández, Francisco Cavallé Sesé, and Lorenzo Fernández Gonzalo, "Diseño de Electrodos de Puesta a Tierra Mediante la Técnica de Elementos Finitos,", 4 ed. 7as Jornadas Hispano Lusas de Ingeniería Eléctrica, Ed. Universidad Carlos III de Madrid, 2001, pp. 47-52.

[3] R. Cortina and A. Porrino, "Calculation of Impulse Current Distributions and Magnetic-Fields in Lightning Protection Structures A Computer-Program and Its Laboratory Validation," IEEE Transactions on Magnetics., vol. 28, no. 2, pp. 1134-1137, Mar.1992.

[4] I. SAS IP, "Release 9.0 Documentation for ANSYS," 2006.

[5] A. Geri, "Behaviour of grounding systems excited by high impulse currents: the model and its validation," IEEE Transactions on Power Delivery., vol. 14, no. 3, pp. 1008-1017, July1999. 